University of Wollongong

Research Online

Faculty of Engineering and Information

Faculty of Engineering and Information

Sciences - Papers: Part A

Sciences

2013

Essential elements in tactical planning models for container liner shipping

Shuaian Wang

University of Wollongong, shuaian@uow.edu.au

Follow this and additional works at: https://ro.uow.edu.au/eispapers

Part of the Engineering Commons, and the Science and Technology Studies Commons

Research Online is the open access institutional repository for the University of Wollongong. For further information contact the UOW Library: research-pubs@uow.edu.au 


\title{
Essential elements in tactical planning models for container liner shipping
}

\begin{abstract}
Tactical planning models for liner shipping problems such as network design and fleet deployment usually minimize the total cost or maximize the total profit subject to constraints including ship availability, service frequency, ship capacity, and transshipment. Most models in the literature do not consider slot-purchasing, multi-type containers, empty container repositioning, or ship repositioning, and they formulate the numbers of containers to transport as continuous variables. This paper develops a mixed-integer linear programming model that captures all these elements. It further examines from the theoretical point of view the additional computational burden introduced by incorporating these elements in the planning model. Extensive numerical experiments are conducted to evaluate the effects of the elements on tactical planning decisions. Results demonstrate that slot-purchasing and empty container repositioning have the largest impact on tactical planning decisions and relaxing the numbers of containers as continuous variables has little impact on the decisions.
\end{abstract}

\section{Keywords}

elements, essential, planning, models, tactical, container, shipping, liner

Disciplines

Engineering | Science and Technology Studies

\section{Publication Details}

Wang, S. (2013). Essential elements in tactical planning models for container liner shipping. Transportation Research Part B: Methodological, 54 84-99. 


\title{
Essential elements in tactical planning models for container liner shipping
}

\author{
Shuaian Wang* \\ School of Mathematics and Applied Statistics, University of Wollongong, Wollongong, \\ NSW 2522, Australia
}

\begin{abstract}
Tactical planning models for liner shipping problems such as network design and fleet deployment usually minimize the total cost or maximize the total profit subject to constraints including ship availability, service frequency, ship capacity, and transshipment. Most models in the literature do not consider slot-purchasing, multi-type containers, empty container repositioning, or ship repositioning, and they formulate the numbers of containers to transport as continuous variables. This paper develops a mixed-integer linear programming model that captures all these elements. It further examines from the theoretical point of view the additional computational burden introduced by incorporating these elements in the planning model. Extensive numerical experiments are conducted to evaluate the effects of the elements on tactical planning decisions. Results demonstrate that slot-purchasing and empty container repositioning have the largest impact on tactical planning decisions and relaxing the numbers of containers as continuous variables has little impact on the decisions.
\end{abstract}

Keywords: container liner shipping, network design, fleet deployment, ship repositioning, totally unimodular matrix

\section{Introduction}

Container liner shipping is the transportation of containerized cargo on regularly scheduled service routes. Global liner container shipping companies such as Maersk Line and OOCL announce their services in terms of

${ }^{*}$ Corresponding author. Email: wangshuaian@gmail.com 
port rotations and schedules on their websites to attract container shipment demand (Song and Dong, 2012; Brouer et al., 2013). Containerships must adhere to the announced port rotations and schedules no matter whether they are fully loaded or not. Unlike tramp shipping where ships operate in view of realized demand, liner shipping companies design their shipping services by anticipating future demand, and the designed services are operated consecutively for a planning horizon of 3 to 6 months (Christiansen et al., 2004). As a consequence, a large proportion of the total operating cost is determined once the liner shipping services are designed.

The design of liner shipping services at the tactical planning level, which covers a planning horizon of 3 to 6 months, mainly involves port rotation design and ship fleet deployment (Wang et al., 2013). Port rotation design determines the itinerary of ships, i.e., which port to visit first, which port to visit second, etc. Port rotation design is often referred to as network design (ND) in liner shipping literature. Fleet deployment (FD) decides the type and number of ships to assign to each port rotation. The input for ND and FD includes port profiles, ship fleet, and container shipment demand. Studies on ND and FD in liner shipping usually minimize the total cost for fulfilling all the container shipment demands or maximize the total profit by choosing only profitable containers to transport. The constraints considered generally include ship availability, which indicates that the number of ships deployed cannot exceed the available number of ships; weekly services, which means that each port of call is visited once a week to ensure the required level of service; ship capacity constraint, which implies that ships cannot carry more containers than their loading capacity; and transshipment, which stipulates that containers can be transferred from one ship to another during trips from their origin ports to their destination ports.

In this paper, we analyze 5 elements in container liner shipping that are seldom mentioned in existing tactical planning models. Table 1 summarizes relevant literature, including the problem addressed (network design or fleet deployment), whether the objective minimizes cost or maximizes profit (column "Obj"), whether slot-purchasing is allowed (column "Slot", element 1 ), whether the number of containers transported is modeled as an integer (column "Int", element 2), whether multi-type containers are considered (column "Multi-type", element 3), whether empty container repositioning is incorporated (column "ECR", element 4), and whether ship repositioning is investigated (column "Ship repo", element 5). For a general overview on container liner shipping, see Meng et al. (2013). 
Table 1: Elements incorporated in the literature

\begin{tabular}{rrrrrrrr}
\hline Paper & Problem & Obj & Slot & Int & Multi-type & ECR & Ship repo \\
\hline Shintani et al. (2007) & ND & Profit & No & No & No & Yes & No \\
Agarwal and Ergun (2008) & ND & Profit & No & No & No & No & No \\
Alvarez (2009) & ND & Cost & Yes & No & No & No & No \\
Liu et al. (2011) & FD & Profit & No & No & No & Yes & No \\
Meng and Wang (2011a) & ND & Cost & No & No & No & Yes & No \\
Meng and Wang (2011b) & FD & Profit & No & No & No & No & No \\
Meng and Wang (2012) & FD & Cost & Yes & No & No & No & No \\
Reinhardt and Pisinger (2012) & ND & Cost & No & No & Yes & No & No \\
Wang and Meng (2012a) & FD & Cost & Yes & No & No & Yes & No \\
Wang and Meng (2013) & ND & Cost & Yes & No & No & No & No \\
\hline
\end{tabular}

The first element is slot-purchasing. Similar to airlines, liner shipping companies also cooperate and form alliances to share capacity on assets and infrastructures setup and capital costs. For example, APL, HMM, and MOL form the New World Alliance; Hapag-Lloyd, NYK, OOCL, and MISC form Grand Alliance. A shipping company often purchases ship slots from other members in its alliance if its own shipping capacity is insufficient for demand. Usually the slot-purchasing price is much lower than the market price for shippers. Alvarez (2009) imposed a "penalty cost" for not fulfilling all demands. Meng and Wang (2012), Wang and Meng (2012a) and Wang and Meng (2013)have allowed a shipping company to buy slots to fulfill its demands. We will investigate whether it is reasonable to minimize total cost while fulfilling all the demands and not allowing slot-purchasing.

The second one is integer number of containers. The number of containers that are handled or transported is an integer rather than a fraction. It does not make sense to say "transport 0.5 container from port A to port B". Tactical planning models generally formulate the numbers of containers as continuous variables rather than integers because the numbers of containers are usually large (i.e., not 2, 3, or 4, but 50, 100, or 200) and cannot be predicted accurately. We hence need to examine whether such a relaxation affects tactical planning decisions.

The third one is multi-type containers. In reality, a containership transports many different types of containers, for example, 20-ft dry containers (D20), 40-ft dry containers (D40), 20-ft reefer containers (R20), 40-ft reefer containers (R40). Most models incorporate only one type of container, that is, twenty-foot equivalent units (TEUs). They generally assume that one D20 is one TEU, and one D40 is equivalent to two TEUs. In terms of volume onboard ships, this transformation is reasonable because a ship slot suitable 
for one D40 can also be used to accommodate two D20s. However, in terms of container handling, the loading cost of a D40 is much smaller than twice the cost of a D20 because both operations involve one quay crane move. A natural question is, what loading cost should be used when modeling only TEUs? We are aware of no studies that mention this issue. In addition to this problem, we will investigate the difference in terms of computational time and optimal tactical decisions between models using TEUs and models with multi-type containers.

The fourth one is empty container repositioning (ECR), which is the result of unbalanced international trade (Song and $\mathrm{Xu}, 2012$ ). Most studies examine ECR at the operational level while Shintani et al. (2007) and Meng and Wang (2011a) have pointed out that incorporating ECR in ND may lead to different network structures. Bell et al. (2011) and Liu et al. (2013) considered both laden and empty containers in a routing problem. Wang and Meng (2012a) formulated both laden and empty containers in fleet deployment models. We further analyze the consequence of ignoring ECR in planning models in a more general setting.

The fifth one is ship repositioning. Ships cannot be ready for any service at any time. For example, if a ship that used to serve intra-Asia demands needs to be deployed on an Europe-America service, it must first sail from Asia to Europe (or America). The associated cost cannot be neglected, although the ship may carry some cargos from Asia to Europe (or America) if the repositioning process is well planned. This type of ship repositioning cost is rarely included in liner shipping models.

The objective of this paper is to investigate from theoretical and numerical viewpoints whether these five elements, namely, (i) slot-purchasing, (ii) integer number of containers, (iii) multi-type containers, (iv) empty container repositioning, and (v) ship repositioning, should be incorporated in tactical planning models. Although ND and FD problems are quite different and require different solution techniques, the impacts of the five elements to them are similar. Hence, we use the example of the FD problem to analyze the five elements. The contributions of this paper are threefold. First, we develop a mixed-integer linear programming model that captures all the above five elements as well as constraints in other studies. Second, we rigorously prove that the ship repositioning sub-problem has the property of total unimodularity, and hence ship repositioning decisions can be modeled as continuous variables. Third, we present examples demonstrating the impacts of the five elements, examine from the theoretical point of view the additional com- 


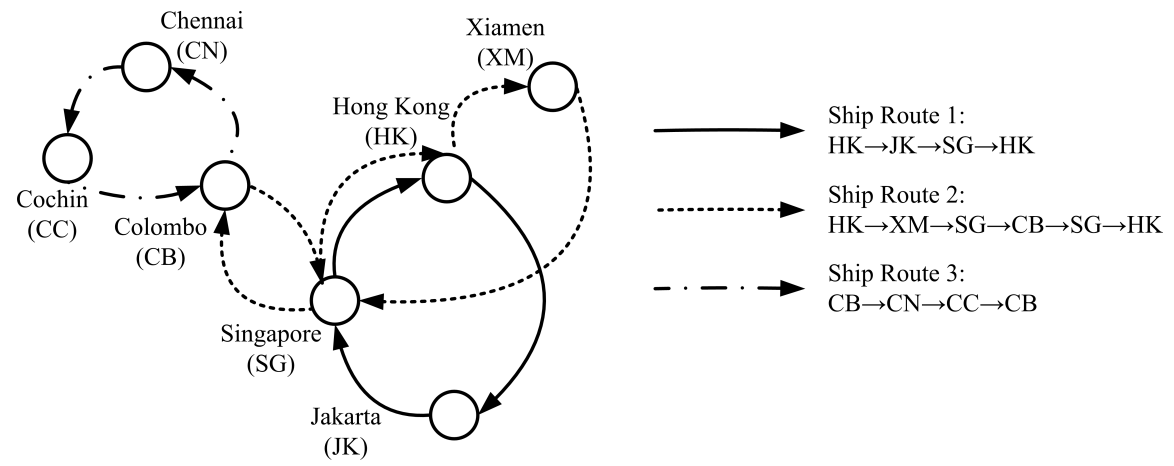

Figure 1: A liner shipping network with three ship routes (Wang and Meng, 2012b)

putational burden introduced by incorporating the elements in the models, and conduct extensive numerical experiments to evaluate the effects of the elements on tactical planning decisions.

The remainder of this paper is organized as follows: Section 2 analyzes the properties of liner shipping operations. Section 3 formulates a mixedinteger linear programming model for the FD problem that captures all the elements, and examines the theoretical properties of the model. Section 4 conducts numerical experiments to evaluate the impact of these elements on tactical planning decisions. Conclusions are presented in Section 5.

\section{Elements of container liner shipping}

We consider a FD problem for a liner container shipping company. This company operates a number of ship routes, denoted by the set $R$, regularly serving a group of ports denoted by the set $P$. The port rotation of a ship route $r \in R$ can be expressed as

$$
p_{r 1} \rightarrow p_{r 2} \rightarrow \cdots \rightarrow p_{r N_{r}} \rightarrow p_{r 1}
$$

where $N_{r}$ is the number of ports of call on the ship route and $p_{r i}$ is the $i$ th port of call. Let $I_{r}$ be the set of ports of call of ship route $r \in R$, i.e., $I_{r}=\left\{1,2, \cdots, N_{r}\right\}$. Defining $p_{r, N_{r}+1}=p_{r 1}$, the voyage from $p_{r i}$ to $p_{r, i+1}$ is called leg $i, i \in I_{r}$. Fig. 1 shows a liner shipping network with three ship 
routes elaborated as follows:

$$
\begin{aligned}
r=1, N_{r}=3: & p_{r 1}(\mathrm{HK}) \rightarrow p_{r 2}(\mathrm{JK}) \rightarrow p_{r 3}(\mathrm{SG}) \rightarrow p_{r 1}(\mathrm{HK}) \\
r=2, N_{r}=5: & p_{r 1}(\mathrm{HK}) \rightarrow p_{r 2}(\mathrm{XM}) \rightarrow p_{r 3}(\mathrm{SG}) \rightarrow p_{r 4}(\mathrm{CB}) \\
& \rightarrow p_{r 5}(\mathrm{SG}) \rightarrow p_{r 1}(\mathrm{HK}) \\
r=3, N_{r}=3: & p_{r 1}(\mathrm{CB}) \rightarrow p_{r 2}(\mathrm{CN}) \rightarrow p_{r 3}(\mathrm{CC}) \rightarrow p_{r 1}(\mathrm{CB})
\end{aligned}
$$

The FD problem determines the type and number of ships to deploy on each ship route. If no ship is deployed on a ship route $r \in R$, then $r$ is not operated. If a ship route $r \in R$ is operated, it must have at least a weekly service frequency since weekly services are a norm in liner shipping. In the sequel, we use weekly costs and week container shipment demands unless otherwise specified.

\subsection{Ships and ship repositioning}

The ships available for deployment are categorized into different types denoted by $V$ according to their load capacities, sailing speeds, operating costs and other ship-specific characteristics. We let $V_{r} \subset V$ be the set of candidate ship types for ship route $r \in R$. To maintain a weekly service frequency, usually a string of ships in the same type, rather than a single ship, is deployed. For example, suppose that in Fig. 1 it takes a 3000-TEU ship four weeks to finish a round-trip on ship route 2 , which consists of time at ports and time at sea (Bell and Bichou, 2008). Then, a string of four 3000TEU ships must be deployed to maintain a weekly service frequency (Qi and Song, 2012). We let $M_{r v}$ be the number of ships required to maintain a weekly service if ships of type $v \in V$ are deployed on ship route $r \in R$. We have $M_{r v}=4$ in the above example. More than one string of ships can be deployed on a ship route. If two strings of 3000-TEU ships (8 ships) and one string of 1500-TEU ships are deployed on ship route 2 , then the ship route has a thrice-weekly service frequency.

To demonstrate the concept of ship repositioning, we use the following example:

Example 1. Suppose that in Fig. 1, currently there are two 3000-TEU ships operating on ship route 1 , four 3000 -TEU ships on ship route 2 , one 1500 TEU ship on ship route 3 , and one 3000-TEU ship in idle at the port of Colombo. Then,

$$
V=\{\text { Type } 1=1500 \text {-TEU ships, Type } 2=3000 \text {-TEU ships }\}
$$


Suppose that $V_{r}=V$, for all $r \in R$.

We further suppose that the company decides that a 3000-TEU ship should be deployed on ship route 3. Then, if the 3000-TEU ship is one that used to serve ship route 2, the ship can "phase out" from ship route 2 when it visits the port of Colombo by discharging the remaining containers onboard and "phase in" to ship route 3. If the 3000-TEU ship is the one in idle at the port of Colombo, then it can start to serve ship route 3 after a little preparation work. In both cases, the repositioning cost of the ship for serving ship route 3 is relatively small. However, if the 3000-TEU ship is one that used to serve ship route 1 , then the ship must be repositioned from the itinerary of ship route 1 to the itinerary of ship route 3 , and the resulting repositioning cost is much larger.

To characterize the repositioning of ships, we define $S_{v}$ to be the set of ship groups that are of type $v \in V$. Ships in the same group must be in the same type and have the same repositioning cost to all the ship routes. Define $S:=\cup_{v \in V} S_{v}$. We further let $M_{s}$ be the number of ships in group $s \in S$ and $\breve{c}_{r s}$ be the repositioning cost of a ship in group $s \in S$ to ship route $r \in R$. In Example 1, ships in type 1 have only one group, i.e., $S_{v_{1}}$ is a singleton $\left\{s_{1}\right\}$, which is the 1500-TEU ship on ship route 3 . We further have $M_{s_{1}}=1, \breve{c}_{r_{2} s_{1}}$ is small, $\breve{c}_{r_{3} s_{1}}$ is small, and $\breve{c}_{r_{1} s_{1}}$ is large. Ships in type 2 have three groups, $S_{v_{2}}=\left\{s_{2}, s_{3}, s_{4}\right\} . s_{2}$ is the group of ships that are operating on ship route $1, M_{s_{2}}=2, \breve{c}_{r_{1} s_{2}}$ is small, $\breve{c}_{r_{2} s_{2}}$ is small, and $\breve{c}_{r_{3} s_{2}}$ is large. $s_{3}$ is the group of ships that are operating on ship route $2, M_{s_{3}}=4, \breve{c}_{r_{1} s_{3}}$ is small, $\breve{c}_{r_{2} s_{3}}$ is small, and $\breve{c}_{r_{3} s_{3}}$ is small. $s_{4}$ is the ship that is in idle at the port of Colombo, $M_{s_{4}}=1, \breve{c}_{r_{2} s_{4}}$ is small, $\breve{c}_{r_{3} s_{4}}$ is small, and $\breve{c}_{r_{1} s_{4}}$ is large.

It should be noted that because it is convenient to consider the weekly cost, $\breve{c}_{r s}$ should be averaged over the planning horizon. For example, if the planning horizon is 15 weeks, and the one-off repositioning cost is $\$ 150,000$, then the average repositioning cost per week is $\$ 10,000$.

\subsection{Multi-type laden containers}

Let $K$ be the set of container types dealt with by the liner shipping company. In the sequel, we use the example of $K=\{\mathrm{D} 20, \mathrm{D} 40\}$ to demonstrate the impact of multi-type containers because they are the most common types of containers. Let $W=P \times P$ be the set of origin-destination (O-D) pairs. The number of laden containers in type $k \in K$ to be transported for O-D pair $(o, d) \in W$ is denoted by $q_{o d}^{k} . q_{o d}^{k}=0$ for all $k \in K$ implies that there 
is no container shipment demand from port $o$ to port $d$. We let $E_{k}$ represent the volume in terms of TEUs of a container in type $k \in K$. For example, $E_{\mathrm{D} 20}=1$ TEU and $E_{\mathrm{D} 40}=2$ TEUs.

Table 2 shows the handling price of D20 and D40 at three ports A, B, and $\mathrm{C}$ provided by a global shipping company, where "L" refers to laden and "E" refers to empty. For confidentiality, port names are not reported. Ports $\mathrm{A}$ and $\mathrm{B}$ are major transshipment ports and Port $\mathrm{C}$ is an export port. According to Table 2, we obtain two observations:

Observation 1. At the same port, the loading, discharging, and transshipment cost of a D40 is less than twice the cost of the same handling operation of a D20, when the D40 and the D20 are both laden or both empty.

Observation 2. At the same port, the transshipment cost of a container is less than the sum of loading cost and discharging cost of the same container.

Observation 1 arises from the fact that the handling of D20 and D40 involves the same quay crane move. Observation 2 arises from the fact that shipping companies are more flexible in choosing transshipment ports than export and import ports, and port operators encourage transshipment where there is spare handling capacity.

Because of Observation 1, a natural question arises: what handling cost should one use when only TEUs are modeled? Apparently, it is unreasonable to use the handling cost of D20, or use half the handling cost of D40. We suggest using the weighted average cost. For example, if two D40s and one D20 are loaded, then the average loading cost per TEU is the sum of the loading cost of two D40s and the loading cost of one D20, divided by 5 TEUs. This approach is straightforward for loading and discharging operations because the percentage of different types of containers can be derived from the container shipment demand (provided that all containers are shipped by the focal company). However, the percentage of different types of transshipment operations at a port may change because it depends on how the containers are transported. To overcome this difficulty, one can either use historical data on the percentage, or simply use the percentage of different types of containers in the overall container shipment demands.

\subsection{Empty container repositioning}

If the company transports 100 laden D20s from Port A to Port B, and 50 laden D20s from Port B to Port A, then Port B will have an accumulation 
Table 2: Container handling costs $(\$ /$ container $)$ at three ports

\begin{tabular}{rrrrrrrr}
\hline Port & Type & Load-L & Discharge-L & Transship-L & Load-E & Discharge-E & Transship-E \\
\hline A & D20 & 248 & 324 & 183 & 243 & 243 & 182 \\
A & D40 & 256 & 332 & 198 & 233 & 233 & 182 \\
B & D20 & 118 & 118 & 145 & 125 & 123 & 145 \\
B & D40 & 148 & 148 & 145 & 182 & 182 & 145 \\
C & D20 & 110 & 110 & 71 & 173 & 102 & N.A. \\
C & D40 & 156 & 156 & 106 & 221 & 149 & N.A. \\
\hline
\end{tabular}

of 50 empty containers that must be repositioned to Port A. If a port has additional empty containers, we call it a surplus port; if it is short of empty containers, we call it a deficit port; otherwise we call it a balanced port.

Most studies on ECR examine the problem at the operational level by assuming that laden container routing is first planned and the residual ship capacity is used to transport empty containers (Song and Dong, 2011a,b; Dong and Song, 2012). The following example demonstrates that such a sequential optimization approach may lead to sub-optimal planning decisions.

Example 2. Fig. 2 illustrates a shipping service network with four ports and four candidate ship routes. The candidate ship routes 1,2, 3 and 4 are deployed with ships of 3000 TEUs, 4000 TEUs, 5000 TEUs and 3000 TEUs, respectively. Suppose that 3000 laden D20s are transported from port 1 to port 2, 4000 laden D20s from port 2 to port 3 and 5000 laden D20s from port 3 to port 4. Hence, ports 1, 2 and 3 are short of 3000, 1000, and 1000 empty D20s, respectively. Port 4 has a total of 5000 surplus empty D20s. We aim to determine which candidate ship routes to operate.

At the planning stage, if only laden containers are considered, then ship routes 1,2 , and 3 are operated and all the laden containers can be transported. Moreover, we can use excess capacity of ships deployed on the three ship routes to reposition the empty containers. That is, 5000 empty D20s are first transported from port 4 to port 3 on ship route 3, 1000 of these empty containers are then discharged at port 3 and 4000 are transshipped to the voyage from port 3 to port 2 on ship route 2 , another 1000 of these 4000 empty D20s are discharged at port 2 and the remaining 3000 are transshipped to the voyage from port 2 to port 1 on ship route 1 and they will finally be discharged at port 1 . Ship route 4 thus should not be operated.

However, this solution incurs high transshipment cost of empty containers since 4000 empty D20s have to be transshipped at port 3 and 3000 are transshipped at port 2. If both laden and empty containers are considered 


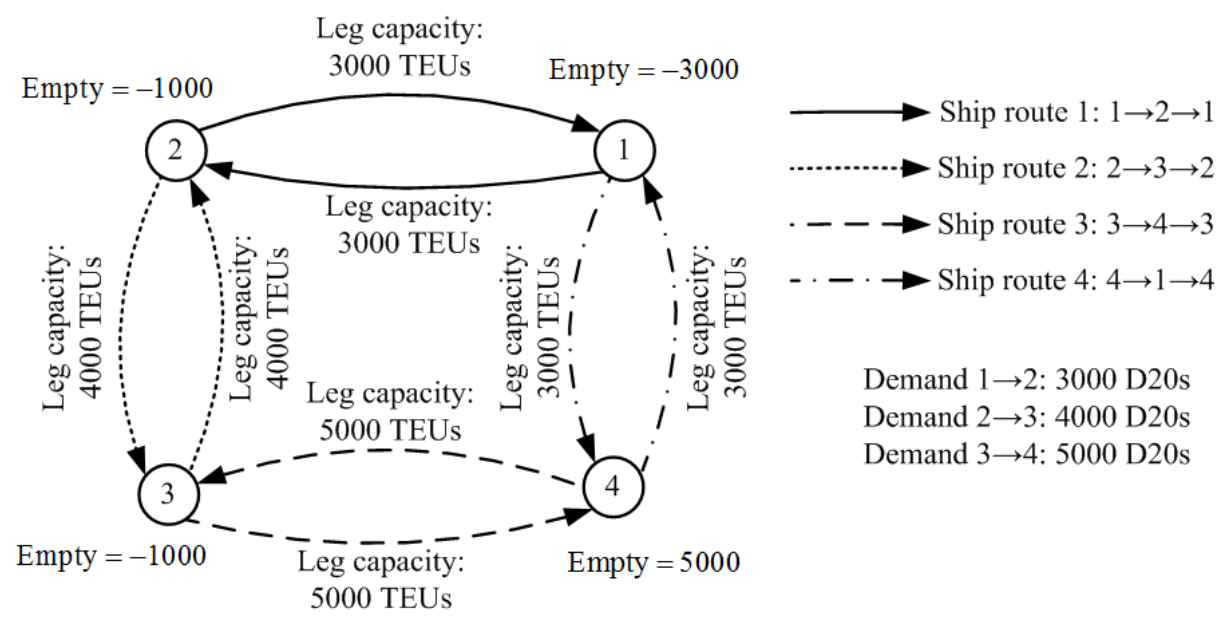

Figure 2: An empty container repositioning problem

in planning and the distance from port 1 to port 4 is very short, then it is more cost-effective to operate all these four ship routes wherein ship route 4 transports 3000 empty D20s from port 4 to port 1 to save the transshipment cost incurred at port 2 and port 3 .

\subsection{Slot-purchasing}

In many studies shown in Table 1, the planning objective is to fulfill the container shipment demands at minimum total operating cost without considering slot-purchasing or allowing dropping some demands. Such a modeling approach may result in unreasonable decisions, as demonstrated by the example below.

Example 3. Consider a company that has 5001 D20s to transport from Singapore to Rotterdam. It has two types of ships: 5000-TEU ships and 6000TEU ships. The company needs to make the optimal ship fleet deployment decision (empty containers are not considered for simplicity).

If we develop a model that aims to transport all the containers at minimum cost, then we will end up choosing 6000-TEU ships. This is unreasonable because the company would not deploy 1000 TEUs' more capacity because of the particular D20 that cannot be shipped. If the model aims to maximize the total profit by choosing the profitable cargo to transport, or if 
the model aims to minimize the total cost of fulfilling the demand while allowing for purchasing slots from other shipping companies ${ }^{1}$, then 5000-TEU ships will be chosen.

Note that alternatively, we can also impose a lost-sale penalty cost while not allowing purchasing slots. Mathematically, there is little difference between the treatments of slot-purchasing and lost-sale cost. Hence, we use the term "slot purchasing" to represent both treatments.

It should be mentioned that Example 3 is very simple and in reality nobody will make the mistake of choosing 6000-TEU ships. However, when deploying ships in a complex network, the deficiencies of ignoring slot-purchasing may not be easily identified by expert judgement. Note further that because of slot-purchasing, the sets of surplus and deficit ports of empty containers cannot be determined a priori as they depend on how many containers are transported by slot-purchasing. Similar to slot-purchasing for laden containers, we also incorporate the possibility of not repositioning all empty containers while incurring a certain penalty cost.

\subsection{Integer number of containers}

In reality the numbers of containers to be handled and transported must be integers and it may not be accurate using continuous variables to model the numbers of containers. We give two examples showing that the optimal container transportation decisions may change if the integrality of the numbers of containers is relaxed.

Example 4. Consider a company that has 4001 D20s and 500 D40s to transport from Singapore to Rotterdam. 5000-TEU ships are deployed. The slotpurchasing cost for a D20 is $\$ 500$ and for a D40 is $\$ 800$. The company needs to determine the minimum slot-purchasing cost (empty containers are not considered for simplicity).

When the numbers of slots to purchase for the two types of containers are modeled as continuous variables, then at the optimal solution half a D40 will be transported by slot-purchasing, and the resulting cost is $\$ 400$. Nevertheless, because of the integrality of the numbers of containers, in reality a

\footnotetext{
${ }^{1}$ The primary goals for slot-purchasing is to take advantage of economies of scale and to expand the service scope. We use Example 3 simply to show that it is unreasonable to require that all the demand must fulfilled by the company in mathematical models.
} 


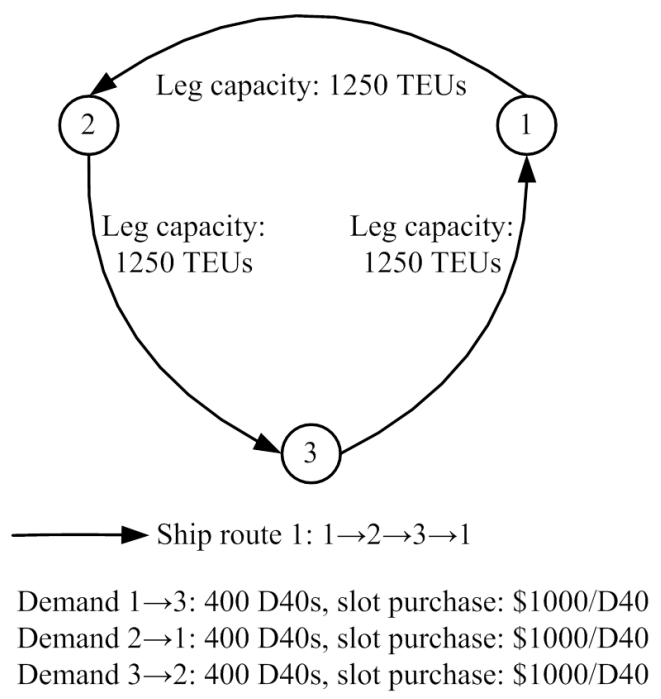

Figure 3: Non-integer number of containers

D20 will eventually be transported by slot-purchasing, and the resulting cost is $\$ 500$.

Example 5. Consider the example in Fig. 3 where 1250-TEU ships are deployed on the ship route. There are three O-D port pairs, each having a demand of 400 D40s. Note that the volume of a D40 is 2 TEUs. The slot-purchasing cost is $\$ 1000 /$ container. The company needs to determine the minimum slot-purchasing cost (empty containers are not considered for simplicity).

When the numbers of containers are modeled as continuous variables, at the optimal solution 312.5 D40s in each O-D port pair are transported by the company itself, that is, a total of $(400-312.5) \times 3=262.5$ D 40 s are transported by slot-purchasing. Nevertheless, because of the integrality of the numbers of containers, one can easily compute that at the optimal solution a total of $88+88+87=263$ D40s are actually transported by slot-purchasing.

Example 5 actually shows that even if there is only one type of container and the demands and ship capacities are all integer multiples of containers, the optimal numbers of containers that are handled and transported can still be non-integer. In spite of Examples 4 and 5, we conjecture that the rational 
behind using continuous variables in the literature is that the numbers of containers are usually very large, and e.g. rounding 321.4 to 321 does not have a considerable effect on the models. Moreover, the difference between the tactical plan and the actual execution/operations could be much larger than the errors caused by treating containers as continuous variables. We will check the validity of the continuous relaxation numerically in Section 4.

\section{A mixed-integer linear programming model}

In this section we develop a mixed-integer linear programming (MIP) model for the FD problem that captures the five elements of slot-purchasing, integer number of containers, multi-type containers, empty container repositioning, and ship repositioning. Although the basic version of the model has only integer decision variables, we will see later that some variables can be relaxed or approximated by continuous variables, and hence we refer to the model as a MIP model. We first list the decision variables, the parameters, and the sets used in the model.

\section{Decision variables}

\section{Fleet deployment variables}

$x_{r v}$ : An integer variable indicating the number of strings of ships in type $v \in V$ deployed on ship route $r \in R$ for maintaining weekly services;

Ship repositioning variables

$m_{r s}$ : Number of ships from group $s \in S$ to be deployed on ship route $r \in R$;

Container transportation variables

$f_{r i}^{o k}$ : Number of containers in type $k \in K$ that originate from port $o \in P$ and are transported on leg $i \in I_{r}$ of ship route $r \in R ; f_{r 0}^{o k}$ is defined as $f_{r N_{r}}^{o k}$;

$f_{r i k}^{e}$ : Number of empty containers in type $k \in K$ that are transported on leg $i \in I_{r}$ of ship route $r \in R ; f_{r 0 k}^{e}$ is defined as $f_{r N_{r} k}^{e}$;

$u_{p k}^{e}$ : Number of surplus empty containers in type $k \in K$ at port $p \in P ; u_{p k}^{e}<0$ if the port is deficit in empty containers in type $k \in K$;

$y_{o d}^{k}$ : Number of containers in type $k \in K$ from port $o \in P$ to port $d \in P$ that are shipped by slot-purchasing;

$y_{p k}^{+e}$ : Number of empty containers in type $k \in K$ that should be repositioned to deficit port $p \in P$ but are not repositioned;

$y_{p k}^{-e}$ : Number of empty containers in type $k \in K$ that should be repositioned from surplus port $p \in P$ but are not repositioned;

$\hat{z}_{r i k}^{e}$ : Number of loading operations (including loading at the surplus port and 
transshipment) of empty containers in type $k \in K$ at the $i$ th port of call on ship route $r \in R, i \in I_{r}$;

$\hat{z}_{r i}^{o k}$ : Number of loading operations (including loading at the origin port and transshipment, as transshipment consists of a discharging operation and a loading operation) of containers in type $k \in K$ that originate from port $o \in P$ at the $i$ th port of call on ship route $r \in R, i \in I_{r}$;

$\tilde{z}_{r i}^{o k}$ : Number of discharging operations (including discharging at the destination port and transshipment) of containers in type $k \in K$ that originate from port $o \in P$ at the $i$ th port of call on ship route $r \in R, i \in I_{r}$;

$\bar{z}_{r i}^{o k}$ : Number of containers in type $k \in K$ that originate from port $o \in P$ and are transshipped at the $i$ th port of call on ship route $r \in R, i \in I_{r}$;

$\tilde{z}_{r i k}^{e}$ : Number of discharging operations (including discharging at the deficit port and transshipment) of empty containers in type $k \in K$ at the $i$ th port of call on ship route $r \in R, i \in I_{r}$;

$\bar{z}_{r i k}^{e}$ : Number of empty containers in type $k \in K$ that are transshipped at the $i$ th port of call on ship route $r \in R, i \in I_{r}$;

$\hat{z}_{p k}$ : Total number of loading operations (including loading at the origin port and transshipment) of laden containers in type $k \in K$ at port $p \in P$;

$\tilde{z}_{p k}$ : Total number of discharging operations (including discharging at the destination port and transshipment) of laden containers in type $k \in K$ at port $p \in P$;

$\bar{z}_{p k}$ : Total number of laden containers in type $k \in K$ that are transshipped at port $p \in P$

$\hat{z}_{p k}^{e}$ : Total number of loading operations (including loading at the surplus port and transshipment) of empty containers in type $k \in K$ at port $p \in P$;

$\tilde{z}_{p k}^{e}$ : Total number of discharging operations (including discharging at the deficit port and transshipment) of empty containers in type $k \in K$ at port $p \in P$;

$\bar{z}_{p k}^{e}$ : Total number of empty containers in type $k \in K$ that are transshipped at port $p \in P$

\section{Parameters}

$c_{r v}$ : Operating cost of one string of ships of type $v \in V$ on ship route $r \in R$;

$\breve{c}_{r s}$ : Repositioning cost of a ship in group $s \in S$ to ship route $r \in R$;

$\hat{c}_{p k}$ : Loading cost of a laden container in type $k \in K$ at port $p \in P$;

$\tilde{c}_{p k}$ : Discharging cost of a laden container in type $k \in K$ at port $p \in P$;

$\bar{c}_{p k}$ : Transshipment cost of a laden container in type $k \in K$ at port $p \in P$;

$\hat{c}_{p k}^{e}$ : Loading cost of an empty container in type $k \in K$ at port $p \in P$;

$\tilde{c}_{p k}^{e}$ : Discharging cost of an empty container in type $k \in K$ at port $p \in P$; 
$\bar{c}_{p k}^{e}$ : Transshipment cost of an empty container in type $k \in K$ at port $p \in P$;

$E_{k}$ : Volume of a container in type $k \in K$;

$\hat{E}_{v}$ : Capacity of a ship in type $v \in V$;

$g_{o d}^{k}$ : Slot-purchasing cost for a laden container in type $k \in K$ from port $o \in P$ to port $d \in P$

$g_{p k}^{+e}$ : Penalty cost for not repositioning an empty container in type $k \in K$ to a deficit port $p \in P$;

$g_{p k}^{-e}$ : Penalty cost for not repositioning an empty container in type $k \in K$ from a surplus port $p \in P$;

$M_{r v}$ : Number of ships required to maintain a weekly service if ships of type $v \in V$ is deployed on ship route $r \in R$;

$M_{s}$ : Number of ships in ship group $s \in S$;

$q_{o d}^{k}$ : Number of laden containers in type $k \in K$ to be transported from port $o \in P$ to port $d \in P$;

\section{Sets}

$I_{r}$ : Set of sequences of ports of call on ship route $r \in R$;

$I_{r p}$ : Set of sequences of calls at port $p \in P$ on ship route $r \in R, I_{r p} \subset I_{r}$;

$K$ : Set of container types;

$P$ : Set of ports;

$R$ : Set of ship routes;

$R_{p}$ : Set of ship routes that visit port $p \in P, R_{p} \subset R$;

$R_{v}$ : Set of ship routes on which ship type $v \in V$ is a candidate;

$S$ : Set of ship groups;

$S_{v}$ : Set of ship groups in ship type $v \in V, S_{v} \subset S$;

$V$ : Set of ship types;

$V_{r}$ : Set of candidate ship types for ship route $r \in R, V_{r} \subset V$;

$W$ : Set of O-D port pairs;

$\mathbb{Z}^{+}$: Set of nonnegative integers.

The FD model can be formulated as: 
[FD]:

$$
\begin{array}{cc}
\min & \sum_{r \in R} \sum_{v \in V_{r}} c_{r v} x_{r v} \\
+ & \sum_{r \in R} \sum_{v \in V_{r}} \sum_{s \in S_{v}} \breve{c}_{r s} m_{r s} \\
+ & \sum_{p \in P} \sum_{k \in K} \hat{c}_{p k}\left(\hat{z}_{p k}-\bar{z}_{p k}\right)+\sum_{p \in P} \sum_{k \in K} \tilde{c}_{p k}\left(\tilde{z}_{p k}-\bar{z}_{p k}\right) \\
+ & \sum_{p \in P} \sum_{k \in K} \bar{c}_{p k} \bar{z}_{p k} \\
+ & \sum_{p \in P} \sum_{k \in K} \hat{c}_{p k}^{e}\left(\hat{z}_{p k}^{e}-\bar{z}_{p k}^{e}\right)+\sum_{p \in P} \sum_{k \in K} \tilde{c}_{p k}^{e}\left(\tilde{z}_{p k}^{e}-\bar{z}_{p k}^{e}\right) \\
+ & \sum_{p \in P} \sum_{k \in K} \bar{c}_{p k}^{e} \bar{z}_{p k}^{e} \\
+ & \sum_{(o, d) \in W} \sum_{k \in K} g_{o d}^{k} y_{o d}^{k} \\
+ & \sum_{p \in P} \sum_{k \in K}\left(g_{p k}^{+e} y_{p k}^{+e}+g_{p k}^{-e} y_{p k}^{-e}\right)
\end{array}
$$


subject to:

$$
\begin{aligned}
& \sum_{r \in R_{v}} M_{r v} x_{r v} \leq \sum_{s \in S_{v}} M_{s}, \forall v \in V \\
& \sum_{s \in S_{v}} m_{r s}=M_{r v} x_{r v}, \forall r \in R, \forall v \in V_{r} \\
& \sum_{r \in R_{v}} m_{r s} \leq M_{s}, \forall v \in V, \forall s \in S_{v} \\
& \sum_{k \in K} E_{k}\left(\sum_{o \in P} f_{r i}^{o k}+f_{r i k}^{e}\right) \leq \sum_{v \in V_{r}} \hat{E}_{v} x_{r v}, \forall r \in R, \forall i \in I_{r} \\
& f_{r, i-1}^{o k}+\hat{z}_{r i}^{o k}=f_{r i}^{o k}+\tilde{z}_{r i}^{o k}, \forall r \in R, \forall i \in I_{r}, \forall o \in P, \forall k \in K \\
& \sum_{r \in R_{d}} \sum_{i \in I_{r d}}\left(\tilde{z}_{r i}^{o k}-\hat{z}_{r i}^{o k}\right)=q_{o d}^{k}-y_{o d}^{k}, \forall o \in P, \forall d \in P \backslash\{o\}, \forall k \in K \\
& y_{o d}^{k} \leq q_{o d}^{k}, \forall o \in P, \forall d \in P, \forall k \in K \\
& f_{r, i-1, k}^{e}+\hat{z}_{\text {rik }}^{e}=f_{\text {rik }}^{e}+\tilde{z}_{\text {rik }}^{e}, \forall r \in R, \forall i \in I_{r}, \forall k \in K \\
& \sum_{r \in R_{p}} \sum_{i \in I_{r p}}\left(\hat{z}_{r i k}^{e}-\tilde{z}_{r i k}^{e}\right)=u_{p k}^{e}+y_{p k}^{+e}-y_{p k}^{-e}, \forall p \in P, \forall k \in K \\
& u_{p k}^{e}=\sum_{o \in P}\left(q_{o p}^{k}-y_{o p}^{k}\right)-\sum_{d \in P}\left(q_{p d}^{k}-y_{p d}^{k}\right), \forall p \in P, \forall k \in K \\
& \hat{z}_{p k}=\sum_{r \in R_{p}} \sum_{i \in I_{r p}} \sum_{o \in P} \hat{z}_{r i}^{o k}, \forall p \in P, \forall k \in K \\
& \tilde{z}_{p k}=\sum_{r \in R_{p}} \sum_{i \in I_{r p}} \sum_{o \in P} \tilde{z}_{r i}^{o k}, \forall p \in P, \forall k \in K \\
& \bar{z}_{p k} \leq \hat{z}_{p k}, \forall p \in P, \forall k \in K \\
& \bar{z}_{p k} \leq \tilde{z}_{p k}, \forall p \in P, \forall k \in K \\
& \hat{z}_{p k}^{e}=\sum_{r \in R_{p}} \sum_{i \in I_{r p}} \hat{z}_{r i k}^{e}, \forall p \in P, \forall k \in K \\
& \tilde{z}_{p k}^{e}=\sum_{r \in R_{p}} \sum_{i \in I_{r p}} \tilde{z}_{r i k}^{e}, \forall p \in P, \forall k \in K \\
& \bar{z}_{p k}^{e} \leq \hat{z}_{p k}^{e}, \forall p \in P, \forall k \in K \\
& \bar{z}_{p k}^{e} \leq \tilde{z}_{p k}^{e}, \forall p \in P, \forall k \in K
\end{aligned}
$$




$$
\begin{array}{r}
x_{r v} \in \mathbb{Z}^{+}, \forall r \in R, \forall v \in V_{r} \\
m_{r s} \in \mathbb{Z}^{+}, \forall r \in R, \forall v \in V_{r}, \forall s \in S_{v} \\
f_{r i}^{o k} \in \mathbb{Z}^{+}, \hat{z}_{r i}^{o k} \in \mathbb{Z}^{+}, \tilde{z}_{r i}^{o k} \in \mathbb{Z}^{+}, \forall r \in R, \forall i \in I_{r}, \forall o \in P, \forall k \in K \\
y_{o d}^{k} \in \mathbb{Z}^{+}, \forall o \in P, \forall d \in P, \forall k \in K \\
f_{r i k}^{e} \in \mathbb{Z}^{+}, \hat{z}_{r i k}^{e} \in \mathbb{Z}^{+}, \tilde{z}_{r i k}^{e} \in \mathbb{Z}^{+}, \forall r \in R, \forall i \in I_{r}, \forall k \in K \\
y_{p k}^{+e} \in \mathbb{Z}^{+}, y_{p k}^{-e} \in \mathbb{Z}^{+}, \forall p \in P, \forall k \in K \\
\hat{z}_{p k} \in \mathbb{Z}^{+}, \tilde{z}_{p k} \in \mathbb{Z}^{+}, \bar{z}_{p k} \in \mathbb{Z}^{+}, \forall p \in P, \forall k \in K \\
\hat{z}_{p k}^{e} \in \mathbb{Z}^{+}, \tilde{z}_{p k}^{e} \in \mathbb{Z}^{+}, \bar{z}_{p k}^{e} \in \mathbb{Z}^{+}, \forall p \in P, \forall k \in K
\end{array}
$$

The objective function (6) minimizes the total cost: the first term is the operating cost of ships on ship routes; the second term is ship repositioning cost; the third term is the laden container loading cost at the origin ports and discharging cost at the destination ports; the fourth term is the laden container transshipment cost; the fifth term is the empty container loading cost at surplus ports and discharging cost at deficit ports; the sixth term is the empty container transshipment cost; the seventh term is the slotpurchasing cost; the eighth term is the penalty cost for not repositioning empty containers.

Eq. (7) imposes that the total number of ships in each type that are deployed does not exceed the number of available ships. Eq. (8) requires that the number of ships taken from all ship groups is equal to the number of ships deployed on a ship route. Eq. (9) enforces that the total number of ships deployed on all ship routes from a ship group does not exceed the number of ships in that group. Note that Eqs. (8) and (9) actually imply Eq. (7). We keep Eq. (7) because it is incorporated in most tactical planning models in the literature whereas Eqs. (8) and (9) are unique to our model which considers ship repositioning. Eq. (10) imposes that the total volume of laden and empty containers flowing on each voyage leg of each ship route does not exceed the capacity of the ships deployed on the ship route. Eq. (11) is the laden container flow conservation equation. Eq. (12) defines that for each port pair, the number of laden containers that are transported by the company's own ships is equal to the demand minus the purchased slots. Eq. (13) requires that the number of containers that are shipped by slot-purchasing does not exceed the demand. Eq. (13) implies that $y_{o d}^{k}=0$ if $q_{o d}^{k}=0$. Eq. (14) is the empty container flow conservation equation. Eq. (15) defines that the number of empty containers that are transported from a port, is equal to the surplus number plus the number of containers that should be repositioned 
to the port minus the number that should be repositioned from the port. Eq. (16) defines the number of surplus empty containers in each type at each port. Eqs. (17) and (18) define the total loading and discharging operations of laden containers, respectively. Eqs. (19) and (20) require that the number of transshipped containers at each port does not exceed the number of loading operations and discharging operations, respectively. Eqs. (21)-(24) define the total loading, discharging, and transshipment operations of empty containers. Eq. (25) defines $x_{r v}$ as a nonnegative integer variable. Eq. (26) defines $m_{r s}$ as a nonnegative integer variable. Eqs. (27)-(32) define all other variables as nonnegative integer variables.

\subsection{Validity of the model}

We let $\left(x_{r v}^{*}, m_{r s}^{*}, y_{o d}^{k *}, u_{p k}^{e *}, y_{p k}^{+e *}, y_{p k}^{-e *}, \hat{z}_{p k}^{*}, \tilde{z}_{p k}^{*}, \bar{z}_{p k}^{*}, \hat{z}_{p k}^{e *}, \tilde{z}_{p k}^{e *}, \bar{z}_{p k}^{e *}\right)$ be an optimal solution to the above model. The model has the following properties.

First, since both $g_{p k}^{+e}$ and $g_{p k}^{-e}$ are greater than 0 , we have $y_{p k}^{+e *} y_{p k}^{-e *}=$ 0 . In words, at least one of the two values $y_{p k}^{+e *}$ and $y_{p k}^{-e *}$ must equal 0 . Second, according to Observation 2, $\bar{c}_{p k}<\hat{c}_{p k}+\tilde{c}_{p k}$. Hence, we have $\bar{z}_{p k}^{*}=$ $\min \left\{\hat{z}_{p k}^{*}, \tilde{z}_{p k}^{*}\right\}$. In other words, using Eqs. (19) and (20) to relax the constraint $\bar{z}_{p k}=\min \left\{\hat{z}_{p k}, \tilde{z}_{p k}\right\}, \forall p \in P, \forall k \in K$ does not change the optimal solution. Third, based on a similar argument for empty container transshipment, we have $\bar{z}_{p k}^{e *}=\min \left\{\hat{z}_{p k}^{e *}, \tilde{z}_{p k}^{e *}\right\}$. Therefore, the model [FD] successfully formulates all the five elements of liner shipping.

\subsection{Computational analysis}

Capturing integer numbers of containers requires the integrality constraints in Eqs. (27)-(32). As demonstrated in Examples 3 and 4, strictly speaking, these integrality constraints cannot be relaxed as continuous constraints. Evidently, the integrality constraints make the problem more difficult to solve.

Allowing slot-purchasing and not repositioning all empty containers introduces a few variables, namely, $y_{o d}^{k}, u_{p k}^{e}, y_{p k}^{+e}, y_{p k}^{-e}$. However, little extra computational burden is imposed for the following reasons. First, the variable $y_{o d}^{k}$ can actually be represented by other variables. Second, the cardinality of $u_{p k}^{e}, y_{p k}^{+e}, y_{p k}^{-e}$ is very small, i.e. $O(|P||K|)$. Third, it is easy to prove

that the integrality constraints on $y_{o d}^{k}, u_{p k}^{e}, y_{p k}^{+e}, y_{p k}^{-e}$ can be relaxed and the resulting optimal solution is still integral. 
Incorporating multi-type containers in the model increases the number of variables roughly to $|K|$ times as large as the model with only TEUs. However, if the numbers of containers are modeled as continuous variables, then incorporating multi-type containers only increases the number of continuous variables and does not increase the number of integer variables $\left(x_{r v}\right.$ and $\left.m_{r s}\right)$. Therefore, the resulting computational burden may be acceptable.

Considering ECR does not make the model much more challenging. In fact, the variables associated with empty containers have scripts $r, i$, and $k$ (e.g., $f_{r i k}^{e}$ ), while variables of laden containers have scripts $r, i, o$, and $k$ (e.g., $\left.f_{r i}^{o k}\right)$. Therefore, in terms of computational time, considering ECR in the model is almost the same as a model without ECR but with one more port in the network.

Modeling ship repositioning introduces more integer variables $m_{r s}$. The number of these new integer variables is usually larger than the number of integer FD variables $x_{r v}$ because $|S| \geq|V|$ and in most cases $|S|$ is several times as large as $|V|$. The large number of integer variables $m_{r s}$ seems to be challenging because (i) the computational time of MIP models increases exponentially with the number of integer variables and (ii) the integer variables $m_{r s}$ lead to a large number of symmetric solutions in the FD problem. However, after carefully examining the model, we identify a nice property:

Theorem 1. The integrality constraints on $m_{r s}$ can be relaxed as continuous constraints because at least in one of the optimal solutions all the $m_{r s}$ variables are integer.

Proof. If we relax the integrality constraints on $m_{r s}$, let $x_{r v}^{*}$ be the optimal fleet deployment decision, then the optimal value of $m_{r s}$ is the solution to the following ship repositioning model (SRM):

[SRM]:

$$
\min \sum_{r \in R} \sum_{v \in V_{r} s \in S_{v}} \breve{c}_{r s} m_{r s}
$$

subject to:

$$
\begin{gathered}
\sum_{s \in S_{v}} m_{r s}=M_{r v} x_{r v}^{*}, \forall r \in R, \forall v \in V_{r} \\
\sum_{r \in R_{v}} m_{r s} \leq M_{s}, \forall v \in V, \forall s \in S_{v} \\
m_{r s} \geq 0, \forall r \in R, \forall v \in V_{r}, \forall s \in S_{v}
\end{gathered}
$$


The right-hand sides of the constraints of $[\mathrm{SRM}]$ are all integers, and hence we only need to prove that the left-hand coefficient matrix of the constraints (34)-(35) of [SRM] is totally unimodular (Nemhauser and Wolsey, 1988). First, all entries of the matrix are either 1 or 0 . Second, each column has exactly two 1's. Third, if we partition the matrix into two, one corresponding to constraint (34), and the other corresponding to constraint (35), then the sum of all entries in each column of either matrix is 1 . Therefore, the coefficient matrix is totally unimodular. As a result, all extreme points of the domain of [SRM] are integral. Hence, at least one optimal solution of $m_{r s}$ is integral and all the extreme optimal solutions are integral.

We turn to Example 1 to better appreciate Theorem 1. Recall that $V=$ $\left\{v_{1}, v_{2}\right\}, S_{v_{1}}=\left\{s_{1}\right\}$, and $S_{v_{2}}=\left\{s_{2}, s_{3}, s_{4}\right\}$. Using matrix form, Eq. (34) is:

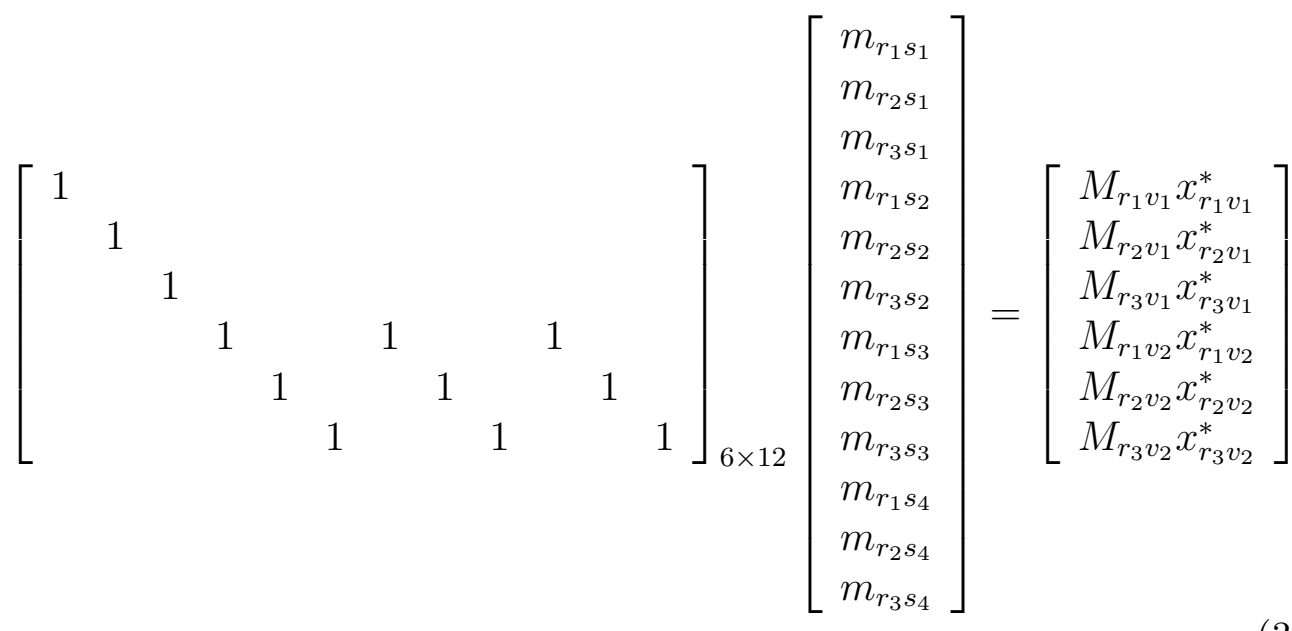

Eq. (35) is: 


$$
\left[\begin{array}{lllllllllll}
1 & 1 & 1 & & & & & & & & \\
& & 1 & 1 & 1 & & & & & & \\
& & & & & 1 & 1 & 1 & & & \\
& & & & & & & 1 & 1 & 1
\end{array}\right]_{4 \times 12}\left[\begin{array}{c}
m_{r_{1} s_{1}} \\
m_{r_{2} s_{1}} \\
m_{r_{3} s_{1}} \\
m_{r_{1} s_{2}} \\
m_{r_{2} s_{2}} \\
m_{r_{3} s_{2}} \\
m_{r_{1} s_{3}} \\
m_{r_{2} s_{3}} \\
m_{r_{3} s_{3}} \\
m_{r_{1} s_{4}} \\
m_{r_{2} s_{4}} \\
m_{r_{3} s_{4}}
\end{array}\right]=\left[\begin{array}{c}
M_{s_{1}} \\
M_{s_{2}} \\
M_{s_{3}} \\
M_{s_{4}}
\end{array}\right]
$$

It is not difficult to see that the combined coefficient matrix of Eqs. (37) and (38) is totally unimodular.

The importance of Theorem 1 lies in that it implies that incorporating ship repositioning will only slightly increase the computational burden because only a small number of continuous variables are introduced.

\section{Numerical experiments}

In this section we conduct randomly generated numerical experiments to see whether the elements - slot-purchasing, integer number of containers, multi-type containers, empty container repositioning, and ship repositioning - affect tactical planning decisions. If an element significantly affects the decisions, then it should be incorporated in the planning models. If an element has a little impact on the decisions, and incorporating it does not increase or only slightly increases the computational difficulty, then it may also be incorporated in the planning models.

The numerical examples are generated as follows. We consider a total of $|P|=20$ ports, uniformly scattered in a $2000 \mathrm{n}$ mile $\times 2000 \mathrm{n}$ mile area. The distance between two ports is assumed to be the length of the line segment connecting the ports. $|R|=5$ ship routes are generated randomly, and each ship route has a maximum of $I_{r}=12$ ports of call. $|V|=2$ types of ships are considered: 1500-TEU ships and 5000-TEU ships. The weekly operating costs of a 1500-TEU ship and a 5000-TEU ship are $\$ 245,000$ and $\$ 560,000$, respectively; the sailing speeds are 15 knots and 20 knots; and the times 
spent at each port of call are 24 hours and 36 hours, respectively. The set of candidate ship types $V_{r}=V$ for all ship routes $r \in R$. The number of ships in a string to maintain a weekly service $M_{r v}$ is calculated by rounding the round-trip time divided by 168 hours/week to the nearest integer (if the nearest integer is 0 , then it is rounded to 1 ). $25 \%$ of port pairs have container shipment demand. If a port pair has demand, its demand (TEUs) is generated from uniform distribution $U(1, x)$, where $x$ can be 100,150 , or 200. At most two types of containers are considered, i.e., D20 and D40. The slot-purchasing cost for a D20 is assumed to be $1000+0.2 \times$ distance of the two ports; the cost for a D40 is $1500+0.4 \times$ distance of the two ports.

The experiments are coded with matlab, and the mixed-integer linear programming models are solved by CPLEX-12.2.

\subsection{Result of slot-purchasing}

We first examine the results with and without considering slot-purchasing. At this step, we only consider D20, assume continuous numbers of containers, and do not incorporate ECR or ship repositioning. The loading, discharging, and transshipment costs for one laden D20 is assumed to be $\$ 120, \$ 120, \$ 150$, respectively, at all ports.

We report the results of 15 randomly generated test instances in Table 3. In instances A01-A05, if an O-D pair has demand, its demand is generated from uniform distribution $U(1,100)$, in B01-B05, the demand is from $U(1,150)$, and in C01-C05, the demand is from $U(1,200)$. Note that we use different random numbers in each instance, and hence the whole networks are different in different instances. The column "Demand" is the total laden container shipment demand (TEUs) over all O-D pairs in the network. For each instance, first, we solve [FD] considering slot-purchasing. Let $\mathbf{x}^{I}$ represent the resulting optimal fleet deployment solution, "CI" (cost 1) be the optimal total cost and "Slot1" be the total volume of containers (TEUs) that are transported by slot-purchasing. Next, we solve [FD] without allowing slot-purchasing, i.e., we add constraint $y_{o d}^{k}=0, \forall o \in P, \forall d \in P, \forall k \in K$ to model $[\mathrm{FD}]^{2}$. Let $\mathbf{x}^{I I}$ represent the resulting optimal fleet deployment solution and "CII" (cost 2) be the optimal total cost. The total volume of containers (TEUs) that are transported by slot-purchasing, denoted by

\footnotetext{
${ }^{2}$ Because the O-D demands are much smaller than the largest candidate ship - 5000 TEUs - the model [FD] always has a feasible solution.
} 
Table 3: Result of slot-purchasing

\begin{tabular}{rrrrrrrrrr}
\hline ID & Demand & CI & Slot1 & CII & Slot2 & (CII-CI)/CI & CIII & Slot3 & (CIII-CI)/CI \\
\hline A01 & 4201 & 4493138 & 187 & 4847210 & 0 & $7.90 \%$ & 4847210 & 0 & $7.90 \%$ \\
A02 & 5226 & 4180140 & 0 & 4180140 & 0 & $0.00 \%$ & 4180140 & 0 & $0.00 \%$ \\
A03 & 5013 & 4318446 & 320 & 4744680 & 0 & $9.90 \%$ & 4744680 & 0 & $9.90 \%$ \\
A04 & 3798 & 4684668 & 222 & 4765400 & 0 & $1.70 \%$ & 4765400 & 0 & $1.70 \%$ \\
A05 & 4330 & 4687888 & 308 & 5175190 & 0 & $10.40 \%$ & 5175190 & 0 & $10.40 \%$ \\
B01 & 6299 & 5277893 & 462 & 5371920 & 0 & $1.80 \%$ & 5371792 & 16 & $1.80 \%$ \\
B02 & 7447 & 6660505 & 970 & 7071220 & 0 & $6.20 \%$ & 7071220 & 0 & $6.20 \%$ \\
B03 & 7458 & 6535977 & 1264 & 7578990 & 0 & $16.00 \%$ & 7578990 & 0 & $16.00 \%$ \\
B04 & 5786 & 4606850 & 0 & 4606850 & 0 & $0.00 \%$ & 4606850 & 0 & $0.00 \%$ \\
B05 & 7337 & 5394926 & 41 & 5561860 & 0 & $3.10 \%$ & 5561860 & 0 & $3.10 \%$ \\
C01 & 10984 & 9333290 & 13 & 9664070 & 0 & $3.50 \%$ & 9664070 & 0 & $3.50 \%$ \\
C02 & 10134 & 8421538 & 1791 & 9589070 & 0 & $13.90 \%$ & 9589070 & 0 & $13.90 \%$ \\
C03 & 8687 & 7729382 & 1533 & 9335250 & 0 & $20.80 \%$ & 9335250 & 0 & $20.80 \%$ \\
C04 & 7368 & 5998383 & 460 & 6870750 & 0 & $14.50 \%$ & 6870750 & 0 & $14.50 \%$ \\
C05 & 11428 & 8543361 & 521 & 8836270 & 0 & $3.40 \%$ & 8836270 & 0 & $3.40 \%$ \\
\hline
\end{tabular}

"Slot2", is 0. Finally, we fix the fleet deployment decision at $\mathbf{x}^{I I}$, allow slot-purchasing, and solve the model again. That is, we solve [FD] by adding the constraint $x_{r v}=x_{r v}^{I I}, \forall r \in R, \forall v \in V_{r}$ and removing the constraint $y_{o d}^{k}=0, \forall o \in P, \forall d \in P, \forall k \in K$. Let "CIII" (cost 3) be the optimal total cost and "Slot3" be the optimal total volume of containers (TEUs) that are transported by slot-purchasing in this situation. Note that if $\mathbf{x}^{I}=\mathrm{x}^{I I}$, then $\mathrm{CI}=\mathrm{CIII}$ and Slot $1=$ Slot 3 .

The column (CII-CI)/CI in Table 3 demonstrates that excluding slotpurchasing leads to an overestimation of the total cost. For example, in instance C03, the resulting cost is $20.80 \%$ higher than the cost allowing slot-purchasing. The column (CIII-CI)/CI in Table 3 implies that ignoring slot-purchasing frequently leads to significantly different and inferior FD decisions. Among the total 15 instances, only in A02 and B04 the FD decisions are the same with and without allowing slot-purchasing. Therefore, it is important to incorporate slot-purchasing in tactical planning models.

In B01, Slot3=16 indicates that although all the containers can be transported by the company itself with the FD decision $\mathbf{x}^{I I}$, it is more cost-effective to purchase some slots. This is because the distances of some port pairs are short, but a number of handling operations are needed if the company transports the containers by itself due to the network structure. As a result, the total handling cost is higher than slot-purchasing cost. 


\subsection{Outcome of integer number of containers}

We then investigate the outcomes of using integer and continuous numbers of containers in the models. At this step, we consider multi-type containers: D20 and D40, allow slot-purchasing, and do not incorporate ECR or ship repositioning. The loading, discharging, and transshipment costs for one laden D20 are assumed to be $\$ 120, \$ 120, \$ 150$, respectively, at all ports; the costs for one laden D40 are $\$ 130, \$ 130, \$ 150$, respectively, at all ports. We report the results of 15 randomly generated test instances in Table 4 . The columns "CI" and "Slot1" correspond to the model with integer numbers of containers, and "CII" and "Slot2" correspond to the model with continuous numbers of containers. The result in column "Slot2" implies that when the numbers of containers are relaxed as continuous variables, in most cases not all container numbers are integer. The column (CII-CI)/CI suggests that relaxing the integrality of numbers of containers frequently underestimates the total cost. However, the underestimation is marginal: less than $0.01 \%$ in all the instances. In addition to the results in Table 4, we find that the optimal FD decisions using integer and continuous numbers of containers are identical for all the 15 instances. Therefore, we conclude that relaxing the integrality of numbers of containers is a good approximation that generally would not lead to sub-optimal decisions.

Note that Table 4 further demonstrates that the relaxed model of [FD] by formulating the numbers of containers as continuous variables is very tight: the relative optimality gap is less than $0.01 \%$ in all the instances. Therefore, even if we impose integer constraints on the numbers of containers, the model can still be computed efficiently after a few number of branch-andbound processes. Note further that if the planning models are solved in a column generation fashion, then the numbers of containers generally cannot be formulated as integer variables because otherwise dual information cannot be obtained.

\subsection{Effect of multi-type containers}

We then test the effects of modeling only TEUs versus incorporating multi-type containers in the formulation. We consider D20 and D40, allow slot-purchasing, use continuous numbers of containers, and do not incorporate ECR or ship repositioning. The loading and discharging costs for one laden D20 are both assumed to be $\$ 120$ at all ports; the costs for one laden D40 are both $\$ 130$ at all ports. The transshipment costs of a laden D20 and a

laden D40 are the same at each port, and are randomly selected from $\{\$ 150$, 
Table 4: Outcome of integer number of containers

\begin{tabular}{rrrrrrr}
\hline ID & Demand & CI & Slot1 & CII & Slot2 & (CII-CI)/CI \\
\hline A06 & 4212 & 4136650 & 0 & 4136575 & 0.00 & $-0.002 \%$ \\
A07 & 4233 & 3633432 & 35 & 3633432 & 35.00 & $0.000 \%$ \\
A08 & 4706 & 4014122 & 275 & 4013744 & 275.50 & $-0.009 \%$ \\
A09 & 4385 & 3800468 & 111 & 3800365 & 110.50 & $-0.003 \%$ \\
A10 & 4130 & 3318962 & 157 & 3318937 & 156.50 & $-0.001 \%$ \\
B06 & 8266 & 6711827 & 807 & 6711803 & 807.00 & $0.000 \%$ \\
B07 & 7494 & 5315544 & 397 & 5315502 & 396.50 & $-0.001 \%$ \\
B08 & 6975 & 4858087 & 356 & 4857985 & 355.50 & $-0.002 \%$ \\
B09 & 6990 & 5212638 & 99 & 5212563 & 99.00 & $-0.001 \%$ \\
B10 & 7239 & 5702881 & 409 & 5702793 & 409.00 & $-0.002 \%$ \\
C06 & 10062 & 7623357 & 1337 & 7623308 & 1337.50 & $-0.001 \%$ \\
C07 & 9199 & 6293250 & 791 & 6293249 & 791.00 & $0.000 \%$ \\
C08 & 9766 & 7453039 & 1424 & 7452845 & 1425.50 & $-0.003 \%$ \\
C09 & 8387 & 6407322 & 711 & 6407252 & 711.50 & $-0.001 \%$ \\
C10 & 10478 & 6983536 & 546 & 6983191 & 545.75 & $-0.005 \%$ \\
\hline
\end{tabular}

$\$ 80$ \}. When modeling only TEUs, we use the following formula to estimate the loading, discharging, and transshipment cost of a TEU at port $p \in P$, denoted by $\hat{c}_{p}^{\mathrm{TEU}}, \tilde{c}_{p}^{\mathrm{TEU}}$, and $\bar{c}_{p}^{\mathrm{TEU}}$, respectively:

$$
\begin{array}{r}
\hat{c}_{p}^{\mathrm{TEU}}=\frac{\sum_{k \in K} \hat{c}_{p k} \sum_{d \in P} q_{p d}^{k}}{\sum_{k \in K} E_{k} \sum_{d \in P} q_{p d}^{k}} \\
\tilde{c}_{p}^{\mathrm{TEU}}=\frac{\sum_{k \in K} \tilde{c}_{p k} \sum_{o \in P} q_{o p}^{k}}{\sum_{k \in K} E_{k} \sum_{o \in P} q_{o p}^{k}} \\
\bar{c}_{p}^{\mathrm{TEU}}=\frac{\sum_{k \in K} \bar{c}_{p k} \sum_{(o, d) \in W} q_{o d}^{k}}{\sum_{k \in K} E_{k} \sum_{(o, d) \in W} q_{o d}^{k}}
\end{array}
$$

We report the results of 15 randomly generated test instances in Table 5 . The columns "CI" and "Slot1" correspond to the model with multi-type containers, and "CII" and "Slot2" correspond to the model with only TEUs. The column (CII-CI)/CI suggests that using only TEUs may overestimate or underestimate the total cost. However, the relative difference is small: less than $0.5 \%$ in all the instances. In addition to the results in Table 5, we find that the optimal FD decisions using multi-type containers and only TEUs are identical for all the 15 instances. Therefore we argue that modeling only TEUs in tactical planning models is acceptable, provided that the handling cost is averaged in a reasonable manner. Note that it is also advantageous to model only TEUs in tactical planning models, and then fix the planning decisions and optimize container flow considering multi-type containers to obtain a more accurate total cost. 
Table 5: Effect of multi-type containers

\begin{tabular}{rrrrrrr}
\hline ID & Demand & CI & Slot1 & CII & Slot2 & (CII-CI)/CI \\
\hline A11 & 4115 & 3803967 & 80.0 & 3810208 & 104.5 & $0.2 \%$ \\
A12 & 5074 & 4675553 & 264.0 & 4684674 & 295.5 & $0.2 \%$ \\
A13 & 4343 & 3908000 & 0.0 & 3905439 & 0.0 & $-0.1 \%$ \\
A14 & 4222 & 3955737 & 32.5 & 3956160 & 36.5 & $0.0 \%$ \\
A15 & 4723 & 4034765 & 192.8 & 4044270 & 257.8 & $0.2 \%$ \\
B11 & 6573 & 5135620 & 0.0 & 5160433 & 0.0 & $0.5 \%$ \\
B12 & 7214 & 5056924 & 295.5 & 5076025 & 308.5 & $0.4 \%$ \\
B13 & 6833 & 4592469 & 397.0 & 4606693 & 447.5 & $0.3 \%$ \\
B14 & 8169 & 5457496 & 28.0 & 5483969 & 28.0 & $0.5 \%$ \\
B15 & 7102 & 5558592 & 405.5 & 5575955 & 431.5 & $0.3 \%$ \\
C11 & 7567 & 5661457 & 89.5 & 5670310 & 58.0 & $0.2 \%$ \\
C12 & 9720 & 7812235 & 1440.5 & 7845945 & 1613.5 & $0.4 \%$ \\
C13 & 10167 & 6952918 & 782.5 & 6988244 & 852.0 & $0.5 \%$ \\
C14 & 10848 & 7444070 & 856.5 & 7469357 & 906.8 & $0.3 \%$ \\
C15 & 9292 & 6824045 & 0.0 & 6857406 & 0.0 & $0.5 \%$ \\
\hline
\end{tabular}

\subsection{Consequence of empty container repositioning}

We then study the consequences of considering and not considering ECR in the models. At this step, we include only D20, allow slot-purchasing, use continuous numbers of containers, and do not incorporate ship repositioning. The loading and discharging costs of an empty D20 are both $\$ 80$ at all ports, and the transshipment cost is randomly selected from $\{\$ 120, \$ 60\}$. The penalty $g_{p, \text { D20 }}^{+e}=\$ 200$ and $g_{p, \text { D20 }}^{-e}=\$ 100$ at all ports. We report the results of 15 randomly generated test instances in Table 6 . The columns "CI" and "Slot1" correspond to the model with ECR, whose optimal fleet deployment solution is denoted by $\mathbf{x}^{I}$, "CII" and "Slot2" correspond to the model without ECR (that is, the company does not need to reposition empty containers), whose optimal fleet deployment solution is denoted by $\mathrm{x}^{I I}$, and "CIII" and "Slot3" correspond to the model with ECR while the fleet deployment decision is fixed at $\mathbf{x}^{I I}$. "Slot1", "Slot2", and "Slot3" refer to laden containers only. The column (CII-CI)/CI suggests that ignoring ECR will underestimate the total cost by up to $5.6 \%$ (instance C17). The column (CIII-CI)/CI demonstrates that in 5 of the 15 instances, we have $\mathbf{x}^{I} \neq \mathbf{x}^{I I}$. In other words, in one third of the instances, ignoring ECR leads to suboptimal FD decisions. Therefore, we suggest including ECR in all tactical planning models.

\subsection{Impact of ship repositioning}

Finally, we work on the impacts of ship repositioning. At this step, we include only D20, allow slot-purchasing, use continuous numbers of contain- 
Table 6: Consequence of empty container repositioning

\begin{tabular}{rrrrrrrrrr}
\hline ID & Demand & CI & Slot1 & CII & Slot2 & (CII-CI)/CI & CIII & Slot3 & (CIII-CI)/CI \\
\hline A16 & 5281 & 5214477 & 807 & 5041001 & 416 & $-3.3 \%$ & 5248545 & 416 & $0.65 \%$ \\
A17 & 4139 & 4113230 & 0 & 3944220 & 0 & $-4.1 \%$ & 4113230 & 0 & $0.00 \%$ \\
A18 & 5605 & 5001929 & 151 & 4815729 & 151 & $-3.7 \%$ & 5001929 & 151 & $0.00 \%$ \\
A19 & 4947 & 4418745 & 158 & 4186200 & 120 & $-5.3 \%$ & 4418745 & 158 & $0.00 \%$ \\
A20 & 4283 & 4132980 & 0 & 3922900 & 0 & $-5.1 \%$ & 4132980 & 0 & $0.00 \%$ \\
B16 & 7719 & 6773298 & 1769 & 6659604 & 1769 & $-1.7 \%$ & 6773298 & 1769 & $0.00 \%$ \\
B17 & 6206 & 5997953 & 828 & 5712930 & 0 & $-4.8 \%$ & 6072960 & 0 & $1.25 \%$ \\
B18 & 8701 & 7379607 & 356 & 6995453 & 322 & $-5.2 \%$ & 7379607 & 356 & $0.00 \%$ \\
B19 & 7019 & 6507116 & 646 & 6176680 & 0 & $-5.1 \%$ & 6607040 & 0 & $1.54 \%$ \\
B20 & 7075 & 5722851 & 1073 & 5552375 & 1073 & $-3.0 \%$ & 5722851 & 1073 & $0.00 \%$ \\
C16 & 10471 & 8078831 & 1246 & 7893044 & 1246 & $-2.3 \%$ & 8078831 & 1246 & $0.00 \%$ \\
C17 & 11002 & 9439431 & 2639 & 8910120 & 0 & $-5.6 \%$ & 9517200 & 0 & $0.82 \%$ \\
C18 & 10188 & 8655450 & 2180 & 8252009 & 2131 & $-4.7 \%$ & 8655450 & 2180 & $0.00 \%$ \\
C19 & 12270 & 9411383 & 420 & 9021470 & 122 & $-4.1 \%$ & 9434769 & 122 & $0.25 \%$ \\
C20 & 10134 & 8362250 & 908 & 7971723 & 733 & $-4.7 \%$ & 8362250 & 908 & $0.00 \%$ \\
\hline
\end{tabular}

ers, and incorporate ECR. Note that the ship repositioning decision variables $m_{r s}$ can be modeled as continuous variables. The ship groups are defined as follows. We first randomly select one string of ships from the two types of ships on each ship route; the number of the ships is exactly enough to maintain a weekly service of the ship route. Hence, we obtain $|R|$ ships groups, denoted by $s_{1}, s_{2}, \ldots, s_{|R|}$. We then randomly choose two ports, and one port has ten 1500-TEU ships and the other port has ten 5000-TEU ships. These two ship groups are denoted by $s_{|R|+1}$ and $s_{|R|+2}$. Therefore, we have a total of $|R|+2$ ship groups. The repositioning cost $\breve{c}_{r s}$ is equal to the repositioning time multiplied by the operating cost of a ship. The repositioning time from a ship in $s_{|R|+1}$ or $s_{|R|+2}$ to a ship route $r \in R$, is the sailing time from the port at which the ship stays to the nearest port on ship route $r \in R$, plus 3.5 days to account for preparation. The repositioning time from a ship in $s_{1}, s_{2}, \ldots, s_{|R|}$ to a ship route $r \in R$, is the sailing time between the nearest two ports on these two ship routes, plus 3.5 days to account for preparation, and plus a random number between 0 and 3.5 days to account for cargo handling. The ship repositioning cost is averaged over a planning horizon of 15 weeks.

We report the results of 15 randomly generated test instances in Table 7 . The columns "CI" and "Slot1" correspond to the model with ship repositioning, whose optimal fleet deployment solution is denoted by $\mathbf{x}^{I}$, "CII" and "Slot2" correspond to the model without ship repositioning, whose optimal fleet deployment solution is denoted by $\mathrm{x}^{I I}$, and "CIII" and "Slot3" correspond to the model with ship repositioning while the fleet deployment 
Table 7: Impact of ship repositioning

\begin{tabular}{rrrrrrrrrr}
\hline ID & Demand & CI & Slot1 & CII & Slot2 & (CII-CI)/CI & CIII & Slot3 & (CIII-CI)/CI \\
\hline A21 & 4852 & 4999016 & 471 & 4863733 & 471 & $-2.7 \%$ & 4999016 & 471 & $0.0 \%$ \\
A22 & 4830 & 4954686 & 812 & 4810079 & 812 & $-2.9 \%$ & 4954686 & 812 & $0.0 \%$ \\
A23 & 4344 & 3965713 & 78 & 3863109 & 78 & $-2.6 \%$ & 3965713 & 78 & $0.0 \%$ \\
A24 & 6113 & 6397711 & 720 & 6258095 & 720 & $-2.2 \%$ & 6397711 & 720 & $0.0 \%$ \\
A25 & 4637 & 5236381 & 491 & 5070205 & 491 & $-3.2 \%$ & 5236381 & 491 & $0.0 \%$ \\
B21 & 6625 & 6195240 & 555 & 6047046 & 555 & $-2.4 \%$ & 6195240 & 555 & $0.0 \%$ \\
B22 & 7134 & 7048167 & 0 & 6856210 & 0 & $-2.7 \%$ & 7048167 & 0 & $0.0 \%$ \\
B23 & 6584 & 7032473 & 0 & 6851230 & 0 & $-2.6 \%$ & 7032473 & 356 & $0.0 \%$ \\
B24 & 6733 & 6152914 & 431 & 6014264 & 431 & $-2.3 \%$ & 6152914 & 431 & $0.0 \%$ \\
B25 & 7843 & 7073395 & 888 & 6914703 & 888 & $-2.2 \%$ & 7073395 & 888 & $0.0 \%$ \\
C21 & 8859 & 7425160 & 1415 & 7276808 & 1415 & $-2.0 \%$ & 7425160 & 1415 & $0.0 \%$ \\
C22 & 9738 & 8168078 & 579 & 7989850 & 0 & $-2.2 \%$ & 8185350 & 0 & $0.2 \%$ \\
C23 & 9392 & 7966028 & 2185 & 7819476 & 2185 & $-1.8 \%$ & 7966028 & 2185 & $0.0 \%$ \\
C24 & 8318 & 7524902 & 739 & 7319118 & 739 & $-2.7 \%$ & 7524902 & 739 & $0.0 \%$ \\
C25 & 9610 & 8034092 & 1546 & 7886146 & 1546 & $-1.8 \%$ & 8034092 & 1546 & $0.0 \%$ \\
\hline
\end{tabular}

decision is fixed at $\mathbf{x}^{I I}$. "Slot1", "Slot2", and "Slot3" refer to laden containers only. The column (CII-CI)/CI suggests that ignoring ship repositioning will underestimate the total cost by up to $3.2 \%$ (instance A25). The column (CIII-CI)/CI demonstrates that in 1 of the 15 instances, we have $\mathbf{x}^{I} \neq \mathbf{x}^{I I}$. In other words, in only one instance, ignoring ship repositioning leads to suboptimal FD decisions, and the relative difference of the cost is $0.2 \%$ (instance C22). Therefore it is generally safe to make tactical planning decisions without considering ship repositioning. Note that it is possible to model tactical planning problems without ship repositioning, and then fix the planning decisions and examine ship repositioning cost to obtain a more accurate total cost.

\section{Conclusions}

We have examined the impact of five elements - slot-purchasing, integer number of containers, multi-type containers, empty container repositioning, and ship repositioning - on tactical planning models for container liner shipping. We have presented examples to demonstrate that in theory all these elements may affect tactical planning decisions. To analyze the effects of incorporating/ignoring the elements in planning models on computational efficiency and on the tactical decisions, we have developed a mixed-integer linear programming model that captures all these elements. Theoretical analysis shows that incorporating slot-purchasing and empty container repositioning has little impact on the computational efficiency of the planning models; considering integer number of containers and multi-type containers will increase 
the number of integer variables and continuous variables, respectively, and hence adversely affect the computational time; including ship repositioning has a marginal consequence on the computational time of the models as the ship repositioning sub-problem has the integrality property due to its totally unimodular coefficient matrix of the constraints. Extensive numerical experiments demonstrate that slot-purchasing and empty container repositioning have the largest impact on tactical planning decisions and relaxing the numbers of containers as continuous variables has little impact on the decisions. Therefore, we suggest incorporating slot-purchasing and empty container repositioning in all tactical planning models. Multi-type containers and ship repositioning may be included if the resulting planning models are tractable. If they are not included in planning models, after the tactical decisions are obtained, the total cost should be re-calculated while considering multi-type containers and ship repositioning by fixing the tactical decisions at the obtained value. The numbers of containers can be modeled as continuous variables without affecting or with little effect on tactical planning decisions and the total cost.

\section{Acknowledgements}

We thank two anonymous reviewers for their valuable comments that have significantly improved the presentation of the paper. This study is supported by the research grant FIRDS of University of Wollongong.

\section{References}

Agarwal, R., Ergun, O., 2008. Ship scheduling and network design for cargo routing in liner shipping. Transportation Science 42 (2), 175-196.

Alvarez, J., 2009. Joint routing and deployment of a fleet of container vessels. Maritime Economics and Logistics 11 (2), 186-208.

Bell, M., Bichou, K., 2008. An analysis into speed and schedule stability for container liner services. Maritime Economics and Logistics 10 (1), 175-184.

Bell, M., Liu, X., Angeloudis, P., Fonzone, A., Hosseinloo, S., 2011. A frequency-based maritime container assignment model. Transportation Research Part B 45 (8), 1152-1161. 
Brouer, B., Dirksen, J., Pisinger, D., Plum, C., Vaaben, B., 2013. The Vessel Schedule Recovery Problem (VSRP) - A MIP model for handling disruptions in liner shipping. European Journal of Operational Research 224 (2), 362-374.

Christiansen, M., Fagerholt, K., Ronen, D., 2004. Ship routing and scheduling: Status and perspectives. Transportation Science 38 (1), 1-18.

Dong, J., Song, D., 2012. Lease term optimisation in container shipping systems. International Journal of Logistics: Research and Applications 15 (2), 87-107.

Liu, X., Bell, M., Angeloudis, P., 2013. A cost-based maritime container assignment model. Transportation Research Part B, in review.

Liu, X., Ye, H.-Q., Yuan, X.-M., 2011. Tactical planning models for managing container flow and ship deployment. Maritime Policy and Management 38 (5), 487-508.

Meng, Q., Wang, S., 2011a. Liner shipping service network design with empty container repositioning. Transportation Research Part E 47 (5), 695-708.

Meng, Q., Wang, S., 2012. Liner ship fleet deployment with week-dependent container shipment demand. European Journal of Operational Research $222(2), 241-252$.

Meng, Q., Wang, S., Andersson, H., Thun, K., 2013. Containership routing and scheduling in liner shipping: overview and future research directions. Transportation Science, doi: 10.1287/trsc.2013.0461.

Meng, Q., Wang, T., 2011b. A scenario-based dynamic programming model for multi-period liner ship fleet planning. Transportation Research Part E 47 (4), 401-413.

Nemhauser, G., Wolsey, L., 1988. Integer and Combinatorial Optimization. John Wiley \& Sons, New York.

Qi, X., Song, D., 2012. Minimizing fuel emissions by optimizing vessel schedules in liner shipping with uncertain port times. Transportation Research Part E 48 (4), 863-880. 
Reinhardt, L., Pisinger, D., 2012. A branch and cut algorithm for the container shipping network design problem. Flexible Services and Manufacturing Journal 24 (3), 349-374.

Shintani, K., Imai, A., Nishimura, E., Papadimitriou, S., 2007. The container shipping network design problem with empty container repositioning. Transportation Research Part E 43 (1), 39-59.

Song, D., Dong, J., 2011a. Effectiveness of an empty container repositioning policy with flexible destination ports. Transport Policy 18 (1), 92-101.

Song, D., Dong, J., 2011b. Flow balancing-based empty container repositioning in typical shipping service routes. Maritime Economics and Logistics $13(1), 61-77$.

Song, D., Dong, J., 2012. Cargo routing and empty container repositioning in multiple shipping service routes. Transportation Research Part B 46 (10), $1556-1575$.

Song, D., Xu, J., 2012. An operational activity-based method to estimate $\mathrm{CO}_{2}$ emissions from container shipping considering empty container repositioning. Transportation Research Part D 17 (1), 91-96.

Wang, S., Meng, Q., 2012a. Liner ship fleet deployment with container transshipment operations. Transportation Research Part E 48 (2), 470-484.

Wang, S., Meng, Q., 2012b. Liner ship route schedule design with sea contingency time and port time uncertainty. Transportation Research Part B 46 (5), 615-633.

Wang, S., Meng, Q., 2013. Reversing port rotation directions in a container liner shipping network. Transportation Research Part B 50, 61-73.

Wang, S., Meng, Q., Bell, M., 2013. Liner ship route capacity utilization estimation with a bounded polyhedral container shipment demand pattern. Transportation Research Part B 47 (1), 57-76. 